\title{
The Effect of Maté Extract on Body Weight and Fat Reduction in Obese Women: A Randomized Placebo-controlled Clinical Trial
}

\author{
Ji-Hye Jung ${ }^{1}$, Yang-Im Hur ${ }^{2, *}$ \\ ${ }^{1}$ Institute for Clinical Nutrition, Inje University Seoul Paik Hospital, Seoul; ${ }^{2}$ Obesity Research Institute, Department of Family Medicine, Seoul Paik Hospital, Inje \\ University College of Medicine, Seoul, Korea
}

Background: This study was performed to investigate the effects of Maté extract on body weight and fat content in obese women $\left[25.0 \mathrm{~kg} / \mathrm{m}^{2}\right.$ $\leq$ body mass index $(\mathrm{BMI})<30 \mathrm{~kg} / \mathrm{m}^{2}$ ] aged $20-65$ years after 6 weeks of its administration.

Methods: The randomized, double-blind, placebo-controlled study was conducted in 33 women. Participants took the supplement, either 2 Maté tablets or 2 placebo tablets, twice daily before meals for 6 weeks. Body weight, body mass index (BMI), waist circumference (WC), and various safety parameters were monitored. Body composition was measured by dual-energy X-ray absorptiometry at baseline and after 6 weeks. Results: Average body weight and BMI did not show any significant changes; however, trunk fat percentage significantly decreased in the Maté group compared to that in the placebo group $(-1.24 \%$ vs $-0.16 \%, P=0.03)$. In the Mate group, the body fat percentages showed a tendency to decrease. All safety parameters were within normal ranges in both groups. Two participants, one from each group, reported nausea during the study.

Conclusion: Maté extract significantly reduced trunk fat in obese women after 6 weeks, which indicates that it could improve abdominal fat mass. Furthermore, the supplement is safe and well tolerated.

Key words: Maté extract, Obese women, Body weight, Body fat, Trunk fat

\section{Introduction}

Recently, the prevalence of obesity has been increasing because of diet westernization and sedentary lifestyles. Thus, obesity has become a serious social issue. ${ }^{1}$ Obesity itself can interfere with daily life, but the more serious problem is that it leads to several diseases such as fatty liver, hypertension, diabetes, and cardiovascular diseases. ${ }^{2,3}$

A recent report on national health statistics published in 2012 by the Ministry of Health \& Welfare indicates that $36.3 \%$ of Korean men and $28.0 \%$ of women, aged 19 years or older, are obese. ${ }^{4}$ The prevalence rate of obesity among elementary, middle, and highschool students increased from $13.2 \%$ in 2009 to $15.3 \%$ in 2013, and the incidence rate of extreme obesity reached $1.5 \%$ in 2013 . The number of obese children and teenagers has been consistently increasing. This increase in the size of the obese population might lead to an increased prevalence of chronic diseases. In addition, accord- ing to the Korea Institute for Health and Social Affairs, social and economic expenses spent on obesity reached 1.8 trillion won in $2011 .{ }^{5}$ It was also found that medical expenses spent on child and adolescent obesity accounted for $10 \%$ of the National Health Service's budget in 2010, and approximately 23.2 billion won had been claimed from the National Health Insurance Corporation for child and adolescent obesity as well as other obesity-related diseases for the past 5 years. ${ }^{6}$

The most effective method for obesity management involves simultaneous diet control, exercise, and lifestyle modification. However, since this method requires time and effort, it is deemed that the use of anti-obesity medications or diet products (i.e., functional foods) may be another useful way to manage obesity. ${ }^{7}$ The 13 functional foods for which weight loss effects have been verified are Garcinia cambogia extract, conjugated linoleic acid (free fatty acids and triglycerides), green Maté extract, green tea extract, soybean sprout
*Corresponding author Yang-Im Hur (iD http://orcid.org/0000-0002-2633-9980 Department of Family Medicine, Seoul Paik Hospital, 9 Mareunnae-ro, Jung-gu, Seoul 04551, Korea

Tel: +82-2-2270-0960 Fax: +82-2-2272-0908 E-mail:yangimhur@gmail.com Received Sep. 23, 2015 Reviewed Oct. 30, 2015 Accepted Dec. 16, 2015
Copyright ( $(2016$ Korean Society for the Study of Obesity

() This is an Open Access article distributed under the terms of the Creative Commons Attribution Non-Commercial License (http://creativecommons.org/licenses/by-nc/4.0/) which permits unrestricted non-commercial use, distribution, and reproduction in any medium, provided the original work is properly cited. 
extract, Melissa officinalis extract, medium chain fatty acids containing oils, Coleus forskohlii extract, hibiscus extract, sesame leaf extract, L-carnitine tartrate, and diglycerides from vegetable oils. ${ }^{8}$

Maté has been a popular drink in foreign countries for a long time, where it was consumed more commonly than coffee, and was used in diet as an invigorant. ${ }^{9}$ In particular, Maté acts on the nervous, digestive, and immune systems to help clear the mind, induce a feeling of well-being, decrease fatigue during exercise, promote metabolism, control appetite, and control the immune system. ${ }^{10}$ It has been introduced not only in South America, but also in North America, Europe, Japan, and Taiwan, and has been receiving a positive response from consumers. Furthermore, it has been consumed not only as tea, but also as a functional food in many different forms.

Maté is known to contain various bioactive substances, which include flavonoids (quercetin and lutin), phenols (chlorogenic acids and caffeic acids), caffeine, and saponins. ${ }^{11}$ In an animal model of high-fat diet-induced obesity, a diet containing Maté was found to exert antioxidant and protective effects against DNA damage. Moreover, the Maté diet increased the expression of genes involved in thermogenesis, such as that encoding for the uncoupling protein (UCP) found in brown adipose tissue cells and visceral fat, and also exerted anti-obesity effects by reducing lipogenesis. ${ }^{12,13}$

Research on the weight loss effects of Mate first started in 2001, and it became an active topic of research worldwide. In the first study, obese patients ingested various herbs containing Maté. This resulted in significant weight loss that was attributed to food staying inside the subjects' stomachs for a longer period of time, and therefore, a shorter period of hunger experienced by these subjects. ${ }^{9}$ In another study, it was observed that Maté ingestion by healthy adults resulted in lower blood cholesterol levels. ${ }^{14}$ In a prospective study, obese women aged 20 to 39 years experienced significant reductions in total body fat and body fat percentages through Maté ingestion..$^{15}$ However, these studies have only targeted healthy adults, obesity patients, American and European populations ${ }^{14}$, or obese women aged between 20 and $39 .{ }^{15}$ Thus, there is still a lack of research on the generally obese (mildly and moderately obese) adults. ${ }^{914}$ Therefore, this study aimed to demonstrate the effectiveness of "Maté extract", whose weight and fat loss effects have been previously verified in numerous prospective studies, in Korean adults aged 20 to 65 years over a 6 week study period.

\section{Methods}

\section{Study subjects}

This study was conducted after being approved from the Institutional Review Board of Inje University Seoul Paik Hospital (IRB No. SIT-2014-295). Subjects who were aged from 20 to 65 years with a BMI between 25.0 and $30.0 \mathrm{~kg} / \mathrm{m}^{2}$ were selected for the study. In accordance with the Helsinki Declaration, all subjects were informed about the purpose of this study and the problems that may occur during the study period in detail before they filled out a consent form. Details regarding the criteria for subject inclusion and exclusion are indicated in Table 1.

\section{Study method}

Among the applicants that applied to participate in the study from September 2014 to December 2014 at Seoul Paik Hospital, 60 adults (41 women, 19 men) were selected, after excluding those who met the exclusion criteria. The number of participants to be involved in this study was calculated using a one-sided two sample $t$-test based on the prospective study results, such that each group contained 24 subjects (expected drop-out rate: $20 \%){ }^{15}$ Subjects were randomly assigned to either the Maté group (case group) or the placebo group (control group). This study provided results for all the subjects (Online Appendix 1), but analyzed only the female subjects' results in detail. The ratio of the numbers of subjects between the two groups was made 1:1, and randomization was performed through a random number assignment to each subject, and then allocating him/her to the group with a random list of numbers, including the number to which the subject corresponds. All doctors, nurses, clinical trial coordinators, and subjects remained blind throughout the whole study period. The study subjects paid a total of 4 visits; measurements performed at each visit are shown in Fig. 1A.

\section{Study product}

Maté extract, found in a light brown powder form, has no smell, but has a unique flavor. ${ }^{8}$ It is acknowledged as a functional ingredient for functional foods within and outside Korea. The product used in this clinical study was in the form of a white, coated tablet, and contained $750.06 \mathrm{mg} /$ tablet. A placebo tablet contained $83.84 \%$ corn starch, $11.71 \%$ crystalline cellulose, $3.50 \%$ hydroxypropyl methylcellulose, $0.80 \%$ magnesium stearate, $0.40 \%$ titanium dioxide, and 
Table 1. Inclusion and exclusion criteria for selection of the study subjects

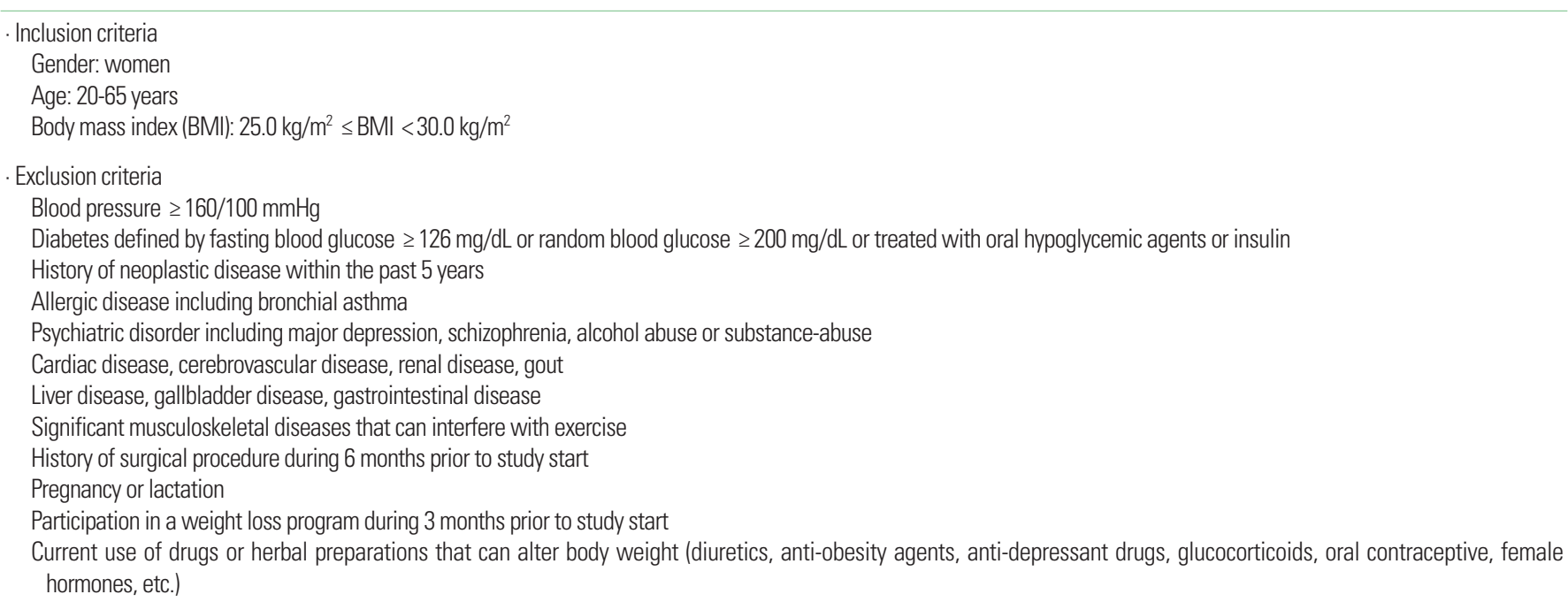

A SCHEDULE

\begin{tabular}{|c|c|c|c|}
\hline -2 week & $\begin{array}{c}0 \text { week } \\
\quad \\
\end{array}$ & $\begin{array}{c}3 \text { week } \\
1\end{array}$ & $\begin{array}{c}6 \text { week } \\
\longrightarrow\end{array}$ \\
\hline & \multicolumn{3}{|c|}{ Education of Diet and Physical Activity } \\
\hline Screening & $1^{\text {st }}$ Test ${ }^{* \neq}$ & $2^{\text {nd }}$ Test $^{* \neq}$ & $3^{\text {rd }}$ Test $^{*+}$ \\
\hline MATE & & & Placebo \\
\hline \multicolumn{4}{|c|}{ Study Participants } \\
\hline $\mathbf{n}=\mathbf{2 3}$ & \multicolumn{2}{|c|}{ Random Allocation } & $\mathbf{n}=\mathbf{1 8}$ \\
\hline $\mathbf{n}=\mathbf{2 1}$ & \multicolumn{2}{|c|}{ Exception of Medium Dropout } & $\mathbf{n}=\mathbf{1 7}$ \\
\hline $\mathbf{n}=\mathbf{1 7}$ & \multicolumn{2}{|c|}{ Over 80\% Dose Rate Participants } & $\mathbf{n}=\mathbf{1 6}$ \\
\hline
\end{tabular}

Figure 1. Intervention schedule and participation in MATE and placebo groups.

*Anthropometric measurement, vital sign; ${ }^{\dagger}$ Body composition analysis, electrocardiogram (ECG), laboratory tests; ${ }^{\ddagger}$ Food diary record.

$0.25 \%$ glycerin fatty acid ester. In the Maté tablet, the Maté extract replaced the $83.34 \%$ of corn starch in the placebo tablet. All the remaining components of the Maté tablet were identical to those of the placebo tablet and in the same proportions. The Maté group took the tablets with water twice per day, 2 tablets per time, 30 minutes before breakfast and dinner, for 6 weeks. The control group did the same, but with the placebo tablets. The total amount of Maté extract intake was $3,000 \mathrm{mg} /$ day during the study period.

\section{Measurement parameters and method}

In order to confirm that the subjects met the qualifications required to participate in the clinical study, body measurements, blood pressure/pulse measurement, blood test, and pregnancy test (for women of childbearing age) were performed 2 weeks before the initial ingestion. On the day of test product distribution, body measurements, body composition analysis, and dietary analysis were performed. After 3 weeks of ingestion, the study subjects visited the 
clinic and had their blood pressure/pulse, side effects, and diet records checked. Safety evaluation was performed to check for any undesirable, unintended symptoms that may have occurred after product ingestion. Safety evaluation included blood tests, physical examinations, electrocardiogram (ECG), and blood pressure/pulse measurements.

\section{1) Body measurements}

Height was measured only on the first visit, while weight was measured every visit. Heights were rounded up to the nearest $0.1 \mathrm{~cm}$. Weight was measured while the subject was in a fasting state and dressed in light clothes, and was rounded up to the nearest $0.1 \mathrm{~kg}$. Body mass index (BMI) was calculated by dividing the body weight in kilograms by the height in meters squared $\left(\mathrm{kg} / \mathrm{m}^{2}\right)$. Waist and hip circumferences were measured starting on the second visit and for every visit afterwards, while having the subject stand on a flat surface. They were rounded up to the nearest $0.1 \mathrm{~cm}$. The waist circumference (WC) was measured at the midpoint between the lowest rib and the highest point of the iliac crest while having the subject stand in an upright posture, and a consistent amount of pressure was applied by the tape measure. On the other hand, the hip circumference (HC) was measured from the point of the highest protrusion on the hip and then around the hip.

\section{2) Body composition test}

Each subject was appointed to a different visit schedule for the test. Dual-energy X-ray absorptiometry (Prodigy ${ }^{\circledR}$ DEXA Lunar, GE Healthcare, Madison, WI, USA) was performed in order to measure body fat percentage (BF\%), body fat mass (BFM), and lean body mass (LBM) after having the subjects take off any metallic accessories such as glasses, necklaces, and watches, and change into comfortable clothes. Body fat distribution results are indicated for arms (left+ right), legs (left+right), trunk, android, and gynoid. Trunk fat signifies all the fat that is distributed in the abdomen, including visceral and subcutaneous fat. Android fat signifies fat in the upper portion of the body, and gynoid fat signifies fat in the hip and the thigh (Fig. 2). ${ }^{16}$

\section{3) Blood test}

Blood samples were collected from the subjects after 8 hours of fasting, and were subjected to hematologic (red blood cell (RBC), hemoglobin ( $\mathrm{Hb})$, hematocrit value (Hct), and platelets) and blood

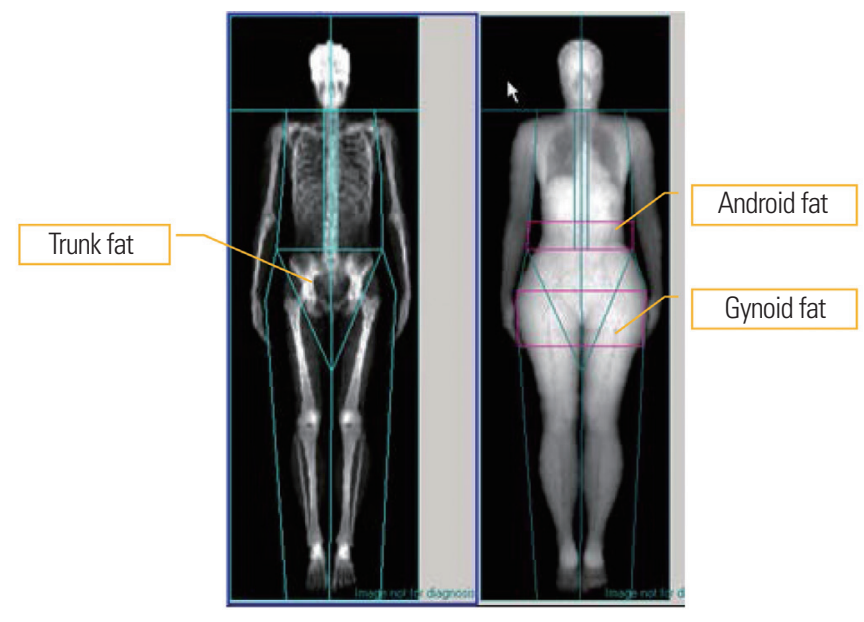

Figure 2. Total body tissue quantitation.

chemical (aspartate aminotransferase (AST), alanine aminotransferase (ALT), protein, albumin, glucose, total bilirubin, and total cholesterol) examinations. Protein, glucose, ketones, and erythrocytes were measured through urinalysis. A pregnancy test (human chorionic gonadotropin, hCG urine test) was performed on women of childbearing age. We followed the protocol set by the central laboratory within the hospital in our blood and urine analyses.

\section{4) Safety evaluation}

Safety evaluation involved blood pressure (BP) measurement, pulse monitoring, ECG, and liver functions (protein, albumin, AST, ALT, and total bilirubin), as well as other physical examinations based on clinical symptoms reported by the subject at the visit. Systolic $\mathrm{BP}$, diastolic $\mathrm{BP}$, and pulse rate $(\mathrm{PR})$ were measured every visit by using an electronic manometer after the subject relaxed for more than 10 minutes. ECG was performed on the first and last visit. In addition, we explained to the subjects the possible side effects of Maté extract, and checked if they experienced them. The subjects were asked to report any side effects that occur prior to the visit to the research coordinator.

\section{5) Drug compliance}

After the initial screening, the subjects received the test product for 3 weeks. Drug compliance was evaluated by collecting and counting leftover tablets that the subjects did not ingest. Subjects who had a lower compliance than $80 \%$ at the start of the final evaluation were excluded from the final evaluation. 


\section{6) Dietary analysis}

We recommended that the subjects reduce their daily caloric intake by $500 \mathrm{kcal}$ per day, and maintain their normal amount of physical activity during the study period. A total of 3 visits (second, third, and fourth visit) were made by the subjects, during which their daily energy and nutrient intake were checked. The mean values of the data from the 3-day diet records (two weekdays and one weekend day) were calculated using Can Pro 3.0, and were used for statistical analysis.

\section{Statistical analysis}

This study calculated the mean and standard deviation using IBM SPPS statistics program to investigate the weight and fat loss effects of Maté extract ingestion for 6 weeks in women. A paired $t$-test was performed to analyze body weight, body fat, WC, BP, PR, and blood test results before and after study product ingestion in each group. An independent samples $t$-test was used to analyze the differences between the control and the Maté group. IBM SPSS version 21.0 was used, and significance level was set as $P<0.05$.

\section{Results}

\section{Clinical test participation}

This study analyzed the data corresponding to female subjects only. Relatively few men participated in the study compared to women (41 women, 19 men), and since only 13 of these men showed higher compliance than $80 \%$, men were completely excluded from this study. It was deemed difficult to analyze men and women's data together due to the differences in the body fat amount and distribution between them.

The forty-one female subjects who met the selection criteria participated in the clinical study and were randomly assigned to one of the two groups, Maté group (23 subjects) and the control group (18 subjects). There were 2 drop-outs in the Maté group and one in the control group during the study period. Only the subjects who had higher compliance than $80 \%$ during the 6 -week period were included in the final analysis. Finally, 17 subjects from the Maté group and 16 subjects from the control group were selected as the final participants (Fig. 1B). Clinical test failure rates were higher in the Maté group, with the rates being $26.1 \%$ in the Maté group, and $11.1 \%$ in the control group.
Table 2. Baseline characteristics of the study subjects

\begin{tabular}{lccc}
\hline & Mate group $(\mathrm{n}=17)$ & Placebo group $(\mathrm{n}=16)$ & $P$ value \\
\hline Sex & Female & Female & \\
Age $($ year $)$ & $45.59 \pm 8.93$ & $41.69 \pm 11.38$ & 0.28 \\
Height $(\mathrm{cm})$ & $158.42 \pm 5.97$ & $159.84 \pm 4.81$ & 0.46 \\
Weight $(\mathrm{kg})$ & $69.43 \pm 7.89$ & $68.99 \pm 6.02$ & 0.86 \\
BMl $\left(\mathrm{kg} / \mathrm{m}^{2}\right)$ & $27.58 \pm 1.72$ & $26.97 \pm 1.61$ & 0.30 \\
WC $(\mathrm{cm})$ & $89.38 \pm 5.67$ & $86.63 \pm 6.26$ & 0.19 \\
HC $(\mathrm{cm})$ & $100.38 \pm 5.78$ & $101.47 \pm 4.10$ & 0.16 \\
SBP $(\mathrm{mmHg})$ & $124.00 \pm 15.57$ & $118.31 \pm 9.21$ & 0.21 \\
DBP $(\mathrm{mmHg})$ & $74.94 \pm 12.14$ & $73.44 \pm 8.01$ & 0.68 \\
PR $(\mathrm{bpm})$ & $75.59 \pm 9.12$ & $74.88 \pm 7.85$ & 0.81 \\
Energy intake $(\mathrm{kcal})$ & $1,671.6 \pm 455.9$ & $1,791.2 \pm 418.9$ & 0.45 \\
Carbohydrate $(\mathrm{g})$ & $221.4 \pm 52.0$ & $253.9 \pm 65.8$ & 0.13 \\
Protein $(\mathrm{g})$ & $73.8 \pm 27.4$ & $72.9 \pm 20.9$ & 0.92 \\
Lipid $(\mathrm{g})$ & $54.4 \pm 19.6$ & $56.3 \pm 20.3$ & 0.79 \\
\hline
\end{tabular}

Values are expressed as mean \pm standard deviation and $P$ values are obtained from student $t$-test.

$\mathrm{BMI}$, body mass index; $\mathrm{BF} \%$, body fat percentage; $\mathrm{WC}$, waist circumference; $\mathrm{HC}$, hip circumference; SBP, systolic blood pressure; DBP, diastolic blood pressure; PR, pulse rate.

\section{Basic characteristics of study subjects}

The mean ages of the subjects were $45.59 \pm 8.93$ years in the Maté group and $41.69 \pm 11.38$ years in the control group; showing no significant difference (Table 2). The mean BMI values and body fat percentages did not differ significantly between the 2 groups: the mean BMI was $27.58 \pm 1.72 \mathrm{~kg} / \mathrm{m}^{2}$ and $26.97 \pm 1.61 \mathrm{~kg} / \mathrm{m}^{2}$ in the Maté and the control group, respectively, and the mean body fat percentage was $36.27 \pm 3.56 \%$ and $35.35 \pm 5.28 \%$ in the Mate and the control group, respectively. Daily caloric intake of each subject was calculated from 3 -day food intake records. The mean daily caloric intake was 1,671.6 $\pm 455.9 \mathrm{kcal} /$ day in the Maté group, and $1,791.2 \pm 418.9 \mathrm{kcal} /$ day in the control group. No significant difference was observed between the Mate and the control group with respect to their dietary intakes (Maté group: carbohydrate $221.4 \pm 52.0 \mathrm{~g}$, protein $73.8 \pm 27.4 \mathrm{~g}$, lipid $54.4 \pm 19.6$ g; Control group: carbohydrate $253.9 \pm 65.8$ g, protein 72.9 \pm 20.9 g, lipid $56.3 \pm 20.3$ g) No significant difference in daily energy and nutrition intakes was observed between the 2 groups after 3 and 6 weeks (data not shown). Likewise, no significant difference in BP, $\mathrm{PR}$, and other blood biochemical parameters was observed between the 2 groups after 3 and 6 weeks of the study product ingestion.

\section{Body measurement changes}

After 6 weeks of ingestion, the mean weight loss was $1.67 \pm 1.32 \mathrm{~kg}$ in the Mate group and $1.27 \pm 1.45 \mathrm{~kg}$ in the control group. The mean BMI was reduced by $0.68 \pm 0.55 \mathrm{~kg} / \mathrm{m}^{2}$ in the Maté group and by 0.49 
Table 3. Changes in anthropometric parameters, fat percentage, and total cholesterol after supplementation of green Mate extract for 6 weeks

\begin{tabular}{|c|c|c|c|c|c|c|}
\hline & Group & Baseline & 6 weeks & Pre-post difference* & $P$ value $^{\dagger}$ & $P$ value ${ }^{\ddagger}$ \\
\hline \multirow[t]{2}{*}{ Weight (kg) } & MATE & $69.43 \pm 7.89$ & $67.76 \pm 8.24$ & $-1.67 \pm 1.32$ & 0.55 & 0.41 \\
\hline & Placebo & $68.99 \pm 6.02$ & $67.72 \pm 6.51$ & $-1.27 \pm 1.45$ & 0.57 & \\
\hline & Placebo & $26.97 \pm 1.61$ & $26.47 \pm 1.74$ & $-0.49 \pm 0.57$ & 0.40 & \\
\hline \multirow[t]{2}{*}{ WC (cm) } & MATE & $89.38 \pm 5.67$ & $87.59 \pm 5.66$ & $-1.79 \pm 1.29$ & 0.36 & 0.90 \\
\hline & Placebo & $86.63 \pm 6.26$ & $84.76 \pm 6.21$ & $-1.87 \pm 2.04$ & 0.40 & \\
\hline \multirow[t]{2}{*}{$\mathrm{BF}(\%)$} & MATE & $36.27 \pm 3.56$ & $35.29 \pm 3.91$ & $-0.98 \pm 1.19$ & 0.45 & 0.10 \\
\hline & Placebo & $35.32 \pm 5.28$ & $35.08 \pm 5.50$ & $-0.24 \pm 1.36$ & 0.90 & \\
\hline \multirow[t]{2}{*}{ BFM (kg) } & MATE & $24.05 \pm 4.27$ & $22.86 \pm 4.66$ & $-1.19 \pm 1.05$ & 0.44 & 0.15 \\
\hline & Placebo & $23.34 \pm 5.13$ & $22.76 \pm 5.53$ & $-0.58 \pm 1.33$ & 0.76 & \\
\hline LBM (kg) & MATE & $41.94 \pm 4.37$ & $41.42 \pm 4.24$ & $-0.52 \pm 0.64$ & 0.73 & 0.39 \\
\hline \multirow[t]{2}{*}{ Leg fat $(\%)$} & MATE & $33.28 \pm 5.47$ & $32.65 \pm 5.69$ & $-0.63 \pm 1.27$ & 0.75 & 0.64 \\
\hline & Placebo & $34.61 \pm 5.97$ & $34.19 \pm 6.21$ & $-0.42 \pm 1.29$ & 0.85 & \\
\hline \multirow[t]{2}{*}{ Trunk fat (\%) } & MATE & $41.15 \pm 3.72$ & $39.92 \pm 3.99$ & $-1.24 \pm 1.72$ & 0.36 & 0.03 \\
\hline & Placebo & $38.60 \pm 5.87$ & $38.76 \pm 6.09$ & $0.16 \pm 1.70$ & 0.94 & \\
\hline \multirow[t]{2}{*}{ Android fat (\%) } & MATE & $45.94 \pm 3.38$ & $44.76 \pm 3.59$ & $-1.18 \pm 2.15$ & 0.33 & 0.21 \\
\hline & Placebo & $43.86 \pm 5.53$ & $43.53 \pm 5.95$ & $-0.33 \pm 1.35$ & 0.87 & \\
\hline \multirow[t]{2}{*}{ Gynoid fat (\%) } & MATE & $39.69 \pm 5.10$ & $39.23 \pm 4.70$ & $-0.46 \pm 1.33$ & 0.79 & 0.99 \\
\hline & Placebo & $41.32 \pm 4.79$ & $40.86 \pm 5.12$ & $-0.46 \pm 1.40$ & 0.80 & \\
\hline \multirow[t]{2}{*}{ Total cholesterol (mg/dL) } & MATE & $220.00 \pm 40.79$ & $208.18 \pm 42.58$ & $-11.65 \pm 31.78$ & 0.99 & 0.59 \\
\hline & Placebo & $199.00 \pm 30.23$ & $186.75 \pm 25.94$ & $-12.63 \pm 27.24$ & 0.50 & \\
\hline
\end{tabular}

Values are expressed as mean \pm standard deviation.

${ }^{*}$ Pre-post difference: 6 weeks-baseline; ${ }^{\dagger} P$ value obtained from paired $t$-test within group; ${ }^{\ddagger} P$ value obtained from independent samples $t$-test.

$\mathrm{BMI}$, body mass index; WC, waist circumference; $\mathrm{HC}$, Hip circumference; BF\%, body fat percentage; BFM, body fat mass; LBM, lean body mass.

$\pm 0.57 \mathrm{~kg} / \mathrm{m}^{2}$ in the control group, but no significant difference was observed between the 2 groups before and after the study product ingestion (Table 3). The WC was reduced by $1.79 \pm 1.29 \mathrm{~cm}$ in the Maté group and by $1.87 \pm 2.04 \mathrm{~cm}$ in the control group. Again, the results did not show any significant difference between the 2 groups. Similarly, there was no significant difference in the HC results between the 2 groups.

\section{Body fat and total blood cholesterol change}

On the 6th week, body fat and total cholesterol were reduced in the arms, legs, android, and gynoid fat in both Maté and control groups to a similar degree (Table 3). However, although trunk fat was reduced by $1.24 \pm 1.72 \%$ in the Maté group, it was increased by $0.16 \pm$ $1.70 \%$ in the control group, indicating a significant reduction in the Maté group compared to the control group $(P=0.03)$ (Fig. 3). Blood cholesterol levels decreased in both groups (Maté group: -11.65 \pm $31.78 \mathrm{mg} / \mathrm{dL}$, control group: $-12.63 \pm 27.24 \mathrm{mg} / \mathrm{dL}$ ), but these values

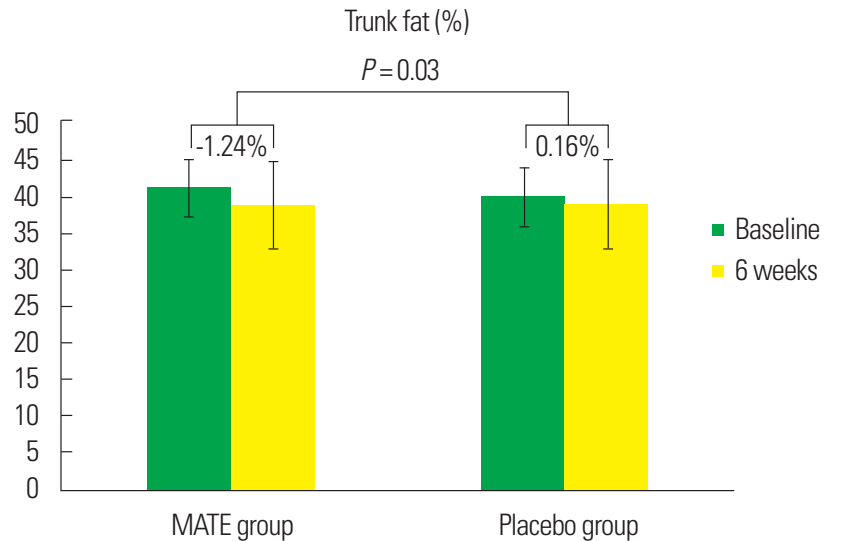

Figure 3. Changes in trunk fat percentage after supplementation of green mate extraction for 6 weeks.

did not differ significantly (Table 3 ).

\section{Safety evaluation results}

In order to test product safety, we looked for changes in liver func- 
Table 4. Changes in safety outcomes after supplementation of green Mate extract for 6 weeks

\begin{tabular}{|c|c|c|c|c|c|c|}
\hline & Group & Baseline & 6 weeks & Pre-post difference ${ }^{*}$ & $P$ value ${ }^{\dagger}$ & $P$ value ${ }^{\ddagger}$ \\
\hline \multirow[t]{2}{*}{ Protein (g/dL) } & MATE & $7.24 \pm 0.24$ & $7.31 \pm 0.32$ & $0.06 \pm 0.24$ & 0.24 & 0.24 \\
\hline & Placebo & $7.24 \pm 0.35$ & $7.20 \pm 0.41$ & $-0.04 \pm 0.38$ & 0.59 & \\
\hline \multirow[t]{2}{*}{ Albumin (g/dL) } & MATE & $4.48 \pm 0.18$ & $4.54 \pm 0.22$ & $0.06 \pm 0.16$ & 0.62 & 0.06 \\
\hline & Placebo & $4.43 \pm 0.24$ & $4.44 \pm 0.20$ & $0.01 \pm 0.23$ & 0.52 & \\
\hline \multirow[t]{2}{*}{ Glucose (mg/dL) } & MATE & $88.88 \pm 9.10$ & $90.71 \pm 5.85$ & $1.82 \pm 7.36$ & 0.16 & 0.39 \\
\hline & Placebo & $91.38 \pm 9.29$ & $88.44 \pm 7.21$ & $-2.94 \pm 5.43$ & 0.42 & \\
\hline \multirow[t]{2}{*}{ AST (IU/L) } & MATE & $25.35 \pm 7.94$ & $29.59 \pm 22.72$ & $4.24 \pm 18.69$ & 0.73 & 0.08 \\
\hline & Placebo & $22.31 \pm 5.51$ & $20.69 \pm 4.09$ & $-1.63 \pm 4.79$ & 0.36 & \\
\hline \multirow[t]{2}{*}{ ALT (IU/L) } & MATE & $26.12 \pm 13.04$ & $26.18 \pm 14.18$ & $0.06 \pm 10.07$ & 0.52 & 0.91 \\
\hline & Placebo & $18.75 \pm 7.73$ & $15.25 \pm 4.09$ & $-3.50 \pm 6.77$ & 0.06 & \\
\hline \multirow[t]{2}{*}{ Total bilirubin (mg/dL) } & MATE & $0.61 \pm 0.14$ & $0.61 \pm 0.11$ & $0.00 \pm 0.17$ & 0.22 & 0.61 \\
\hline & Placebo & $0.68 \pm 0.17$ & $0.70 \pm 0.21$ & $0.02 \pm 0.20$ & 0.71 & \\
\hline \multirow[t]{2}{*}{$\mathrm{SBP}(\mathrm{mmHg})$} & MATE & $124.00 \pm 15.57$ & $118.18 \pm 12.38$ & $-5.82 \pm 12.10$ & 0.24 & 0.71 \\
\hline & Placebo & $118.31 \pm 9.21$ & $113.94 \pm 10.33$ & $-4.38 \pm 9.67$ & 0.22 & \\
\hline \multirow[t]{2}{*}{$\mathrm{DBP}(\mathrm{mmHg})$} & MATE & $74.94 \pm 12.14$ & $75.71 \pm 10.13$ & $0.76 \pm 8.57$ & 0.84 & 0.96 \\
\hline & Placebo & $73.44 \pm 8.01$ & $72.69 \pm 5.39$ & $-0.75 \pm 5.53$ & 0.76 & \\
\hline \multirow[t]{2}{*}{ PR (bpm) } & MATE & $75.59 \pm 9.12$ & $76.94 \pm 9.28$ & $1.35 \pm 9.51$ & 0.67 & 0.59 \\
\hline & Placebo & $74.88 \pm 7.85$ & $73.00 \pm 10.83$ & $-1.88 \pm 8.20$ & 0.60 & \\
\hline
\end{tabular}

Values are expressed as mean \pm standard deviation.

${ }^{*}$ Pre-post difference: 6 weeks - baseline; ${ }^{\dagger} P$ value obtained from paired $t$-test within group; ${ }^{\ddagger} P$ value obtained from independent samples $t$-test.

AST, aspartate aminotransferase; ALT, alanine aminotransferase; SBP, systolic blood pressure; DBP, diastolic blood pressure; PR, pulse rate.

tion indices after product ingestion. In both groups, there were nonsignificant changes in these indices that were within the normal ranges. Systolic BP, diastolic BP, and PR also did not differ significantly between the 2 groups, over the course of the 6 weeks (Table 4).

We also evaluated the adverse effects of the extract experienced by the subjects at a 3-week interval. Two cases of adverse effects, one from each group, were reported in total, and they were both reports of nausea. However, nausea did not last very long and the subjects recovered immediately, and were able to continue participating in the study.

\section{Discussion}

Maté (Ilex paraguariensis St. Hil) is a natural tea that is commonly consumed in South America (Paraguay, Brazil, Argentina, and Uruguay) and is known as one of the world's 3 major drinks alongside coffee and green tea. ${ }^{17}$ In South America, Maté has been traditionally used as a natural substance that boosts the immune system, stabilizes the nervous system, stimulates the mind, controls appetite, treats obesity, reduces stress, and delays aging. It is sold in many countries, aside from South America and the United States, as tea products and food supplements, and no side effects have been reported after its ingestion. ${ }^{18,19}$ No reports of toxicity or side effects were found while searching the safety databases for data regarding the safety of 'Maté' and other Maté-containing products. ${ }^{20,21}$ In addition, several studies on the safety of Maté showed no side effects and have scientifically verified its functionality. ${ }^{12,22}$ In this study, 2 out of the total participants (one from each group, Maté and control) experienced nausea, but it was not regarded as a severe adverse event as it did not last very long and the participants recovered immediately.

Various studies have discovered that chlorogenic acid and triterpenoid saponins, which are components of Maté, promote weight control mechanisms. ${ }^{15,23}$ Therefore, we designed a clinical study to investigate the effects of Maté, whose weight and body fat loss effects have been verified in previous studies, on human subjects. Adults, who were obese but otherwise healthy, were made to ingest $3,000 \mathrm{mg}$ of Maté extract over a 6-week period, and reductions in their body weight and WC were compared to the control group to assess the effectiveness of Maté. We also assessed the safety of Maté by checking for any abnormal symptoms and by performing clinical and laboratory evaluations. As mentioned before, our study holds significance in that it involved a wider range of ages than previous studies, and involved Asian subjects.

In this study, the participants lost an average of $1.67 \pm 1.32 \mathrm{~kg}$ (2.4\%) of their body weight after ingesting Maté extract for 6 weeks. 
This was similar to the result of a prospective study in which overweight women aged between 20 and 35 years were administered Maté extract for 6 weeks, and lost $1.5 \mathrm{~kg}$ (2.1\%) of their body weight by the end of the study period. ${ }^{15} \mathrm{BMI}, \mathrm{WC}$, and systolic BP tended to decrease in the Maté group after 6 weeks, but to a similar degree to those in the control group. Although our study had different criteria regarding the age and degree of obesity for selecting our subjects and was carried out in different research conditions, our results were similar to those of the previous study, and therefore, we believe that our results are meaningful.

Fat oxidation, thermogenesis, and appetite suppression are considered from the main mechanisms by which Maté extract contributes to weight loss. ${ }^{24}$ Saponins contained in Maté act on the surface of micelles and destroy them, leading to a reduction in fat reabsorption and lipogenesis. ${ }^{24}$ Saponins also prevent the binding and absorption of cholesterol in the inner cavity of the intestine, and inhibit fat absorption by inhibiting pancreatic lipase, which can be assessed by measuring respiratory quotient (RQ); a ratio of carbon dioxide exhaled from the body to oxygen consumed. ${ }^{24}$ According to the prospective study result, among the 12 medicinal herbs, only Maté lowered the RQ and showed outstanding effects on body fat loss, which can be attributed to fat oxidation caused by thermogenesis. ${ }^{25}$ Another study reported that Maté stimulates the adrenergic system to suppress appetite. ${ }^{9}$ We believe that even though our results lacked a significant difference from the control group, the reductions in body weight and BMI observed in our study were due to the aforementioned effects of Maté. We also believe that the lack of statistical significance in our results is due to the limiting factors such as the small sample size and the short study period.

While WC is closely associated with trunk fat, HC is closely associated with leg fat and leg lean mass. ${ }^{26} \mathrm{BMI}$ is usually related to total body fat mass. ${ }^{26}$ The result of this study showed that trunk fat was reduced in the Maté group to a more significant degree (-1.24 \pm $1.72 \%)$ than in the control group $(0.16 \pm 1.70 \%)$. On the contrary, the $\mathrm{HC}$ and $\mathrm{BMI}$ did not decrease significantly, and this can be attributed to the fact that the leg fat decreased to a small degree.

Trunk fat reduces the activity of lipoprotein lipase in the blood. This leads to disruptions in lipoprotein metabolism, and to several disorders including type 1 hyperlipoproteinemia. ${ }^{27}$ The significant reduction in trunk fat observed in this study is more clinically meaningful than the reductions in other areas of the body, and this is be- cause trunk fat is directly associated with the blood lipid content. According to a Japanese study that investigated the relation between trunk fat and health, trunk fat contributes to glucose intolerance and hypertension, and also negatively affects apolipoprotein $\mathrm{B} .{ }^{28}$ Similarly, a Norwegian study has reported that the accumulation of trunk fat increases the incidence of insulin resistance and dyslipidemia. ${ }^{29}$ Therefore, the significant reductions in trunk fat in the Maté group observed in this study suggest that long-term ingestion of Maté may also improve dyslipidemia.

This study had some limitations, for example, it was carried out on a small scale; 33 subjects only, and for a short time (6 weeks long). However, the study is meaningful as it objectively evaluates the body weight and fat loss effects of Maté extract in Korean women with varying ages and with a BMI ranging between $25.0 \mathrm{~kg} / \mathrm{m}^{2}$ and 30.0 $\mathrm{kg} / \mathrm{m}^{2}$ through a double-blind randomized placebo-controlled trial.

To summarize our findings, the ingestion of Maté extract over a period of 6 weeks reduced body weight and fat percentage; especially trunk fat was significantly reduced. Therefore, Maté can be considered as a good material for functional foods to be consumed by obese people who are trying to control their weight. However, a long-term clinical study with a more complicated study design and a larger group of subjects would still be needed in the future in order to study the long-term effects of Mate extract on fat loss.

\section{Conflicts of Interest}

The authors declare no conflict of interest.

\section{Acknowledgments}

This research was supported from Medinutra co. in 2014.

\section{References}

1. Kim MK, Lee WY, Kang JH, Kang JH, Kim BT, Kim SM, et al. 2014 clinical practice guidelines for overweight and obesity in Korea. Endocrinol Metab (Seoul) 2014;29:405-9.

2. Jafari-Adli S, Jouyandeh Z, Qorbani M, Soroush A, Larijani B, Hasani-Ranjbar S. Prevalence of obesity and overweight in adults and children in Iran; a systematic review. J Diabetes Metab Disord 2014;13:121. 
3. Payab M, Hasani-Ranjbar S, Larijani B. Whether all obese subjects both in metabolic groups and non-metabolic groups should be treated or not. J Diabetes Metab Disord 2014;13:21.

4. Ministry of Health and Welfare, Korea Centers for Disease Control and Prevention. 2012 National Health Statistics. National Statistical Office [accessed 2015 Jan 17]; Available from: URL: http:// www.index.go.kr/potal/enaraIdx/idxField/userPageCh.do?idx_ $\mathrm{cd}=2705$

5. Jung HW. Severely obese, be must aware of 'dimension of state problem'. Joseilbo [serial online] 2014 May 27 [accessed 2014 Dec 8]; Available from: URL: http://health.joseilbo.com/html/news/?f=r ead\&code $=$ CHILD1333960131\&seq $=8307$

6. Kim JN. Obese Payment for Child and Adolescent, National Health Insurance Corporation Finances 10\%. Newspim [serial online] 2014 Oct 13 [accessed 2014 Dec 9]; Available from: URL: http://www.newspim.com/view.jsp?newsId=20141013000216

7. Khan MI, Anjum FM, Sohaib M, Sameen A. Tackling metabolic syndrome by functional foods. Rev Endocr Metab Disord 2013;14: 287-97.

8. Ministry of Food and Drug Safety. Health Functional Food. Available from: URL: http://www.foodnara.go.kr/hfoodi/

9. Andersen T, Fogh J. Weight loss and delayed gastric emptying following a South American herbal preparation in overweight patients. J Hum Nutr Diet 2001;14:243-50.

10. Santos JC, Gotardo EM, Brianti MT, Piraee M, Gambero A, Ribeiro ML. Effects of yerba maté, a plant extract formulation ("YGD") and resveratrol in 3T3-L1 adipogenesis. Molecules 2014; 19:16909-24.

11. Heck CI, de Mejia EG. Yerba Mate Tea (Ilex paraguariensis): a comprehensive review on chemistry, health implications, and technological considerations. J Food Sci 2007;72:R138-51.

12. Miranda DD, Arçari DP, Pedrazzoli J Jr, Carvalho Pde O, Cerutti SM, Bastos DH, et al. Protective effects of mate tea (Ilex paraguariensis) on $\mathrm{H}_{2} \mathrm{O}_{2}$-induced DNA damage and DNA repair in mice. Mutagenesis 2008;23:261-5.

13. Arçari DP, Bartchewsky W, dos Santos TW, Oliveira KA, Funck A, Pedrazzoli J, et al. Antiobesity effects of yerba maté extract (Ilex paraguariensis) in high-fat diet-induced obese mice. Obesity (Silver Spring) 2009;17:2127-33.

14. de Morais EC, Stefanuto A, Klein GA, Boaventura BC, de Andrade F, Wazlawik E, et al. Consumption of yerba mate (Ilex para- guariensis) improves serum lipid parameters in healthy dyslipidemic subjects and provides an additional LDL-cholesterol reduction in individuals on statin therapy. J Agric Food Chem 2009;57: 8316-24.

15. Kim HJ, Ko J, Storni C, Song HJ, Cho YG. Effect of green mate in overweight volunteers: A randomized placebo-controlled human study. J Funct Foods 2012;4:287-93.

16. Novotny R, Going S, Teegarden D, Van Loan M, McCabe G, McCabe L, et al. Hispanic and Asian pubertal girls have higher android/gynoid fat ratio than whites. Obesity (Silver Spring) 2007; 15:1565-70.

17. Bracesco N, Sanchez AG, Contreras V, Menini T, Gugliucci A. Recent advances on Ilex paraguariensis research: minireview. J Ethnopharmacol 2011;136:378-84.

18. Boaventura BC, Di Pietro PF, Stefanuto A, Klein GA, de Morais EC, de Andrade F, et al. Association of mate tea (Ilex paraguariensis) intake and dietary intervention and effects on oxidative stress biomarkers of dyslipidemic subjects. Nutrition 2012;28:65764.

19. Gao H, Long Y, Jiang X, Liu Z, Wang D, Zhao Y, et al. Beneficial effects of Yerba Mate tea (Ilex paraguariensis) on hyperlipidemia in high-fat-fed hamsters. Exp Gerontol 2013;48:572-8.

20. MEDLINE; Available from: URL: http://www.ncbi.nlm.nih.gov/ pubmed

21. Ministry of Food and Drug Safety; Available from: URL: http:// mfda.go.kr

22. de Andrade F, de Albuquerque CA, Maraschin M, da Silva EL. Safety assessment of yerba mate (Ilex paraguariensis) dried extract: results of acute and 90 days subchronic toxicity studies in rats and rabbits. Food Chem Toxicol 2012;50:328-34.

23. Bojić M, Simon Haas V, Sarić D, Maleš Z. Determination of flavonoids, phenolic acids, and xanthines in Mate tea (Ilex paraguariensis St.-Hil.). J Anal Methods Chem 2013;2013:658596.

24. Resende PE, Verza SG, Kaiser S, Gomes LF, Kucharski LC, Ortega GG. The activity of mate saponins (Ilex paraguariensis) in intraabdominal and epididymal fat, and glucose oxidation in male Wistar rats. J Ethnopharmacol 2012;144:735-40.

25. Martinet A, Hostettmann K, Schutz Y. Thermogenic effects of commercially available plant preparations aimed at treating human obesity. Phytomedicine 1999;6:231-8.

26. Snijder MB, Dekker JM, Visser M, Bouter LM, Stehouwer CD, 
Yudkin JS, et al. Trunk fat and leg fat have independent and opposite associations with fasting and postload glucose levels: the Hoorn study. Diabetes Care 2004;27:372-7.

27. Wang H, Eckel RH. Lipoprotein lipase: from gene to obesity. Am J Physiol Endocrinol Metab 2009;297:E271-88.

28. Kawamoto T, Ishikawa K. Intra-abdominal fat, lipid metabolism and insulin resistance in coronary artery disease. Hypertens Res 1996;19 Suppl 1:S69-74.

29. Aasen G, Fagertun H, Halse J. Insulin resistance and dyslipidaemia in obese premenopausal and postmenopausal women matched for leg/trunk fat mass ratio. Scand J Clin Lab Invest 2009;69:505-11. 